\title{
Optimasi Desain Bucket Tooth Excavator Jenis Verona PC200 Menggunakan Optimasi Topologi dan Metode Elemen Hingga
}

\author{
Sumar Hadi Suryo ${ }^{a}, *$, Rachmat Suryadi Sastra ${ }^{a}, * *$, Muchammad $^{\text {a }}$ \\ aDepartemen Teknik Mesin, Fakultas Teknik, Universitas Diponegoro \\ Jl. Prof. Sudharto, SH., Tembalang-Semarang 50275, Telp. +62247460059 \\ *E-mail: sumarhs.undip@gmail.com;**E-mail: rachmatss@ student.undip.ac.id
}

\begin{abstract}
Excavators are heavy equipment that are usually used to digging soil, cut rock, break roads or knock down buildings. One component that plays a role in this function is bucket tooth. This research discusses the optimization design of bucket tooth on the market to produce a lighter design but still maintains its strength, the bucket tooth is Verona PC200. The optimization process in a bucket tooth applies the concept of topology optimization. The method used includes determining the type of material used by various tests, namely the composition test, micrographic test, and hardness test. Then a static linear analysis is performed using the finite element method to see the maximum stress that occurs in the bucket tooth. the maximum Von-mises value is $403.81 \mathrm{MPa}$. After that topology optimization is done by selecting several variations of the design area which results in a reduction in mass in first variation of $0.72 \mathrm{~kg}$ and the second variation $1.49 \mathrm{~kg}$. The mass reduction causes a change in stress that occurs in the bucket tooth to $451.8 \mathrm{MPa}$ in first variation and $458.6 \mathrm{MPa}$ in variation 2, but the stress is still in a safe condition.
\end{abstract}

Keywords: Bucket tooth; finite element method; topology optimization

\section{Abstrak}

Excavator merupakan alat berat yang biasanya digunakan untuk menggali tanah, membelah batu, membongkar jalan atau merobohkan bangunan. Salah satu komponen yang berperan dalam fungsi tersebut adalah bucket tooth. Pada penelitian ini membahas tentang perancangan optimasi bucket tooth yang ada di pasaran untuk menghasilkan desain yang lebih ringan tetapi tetap mempertahankan kekuatannya, bucket tooth tersebut adalah Verona PC200. Proses optimasi pada bucket tooth menerapkan konsep optimasi topologi. Metode yang dilakukan meliputi penentuan jenis material yang dipakai dengan berbagai pengujian yaitu uji komposisi, uji mikrografi dan uji kekerasan. Kemudian dilakukan analisis linear statik menggunakan metode elemen hingga untuk melihat tegangan maksimum yang terjadi pada bucket tooth, besarnya nilai tegangan Von-mises sebesar 403,81 MPa. Selanjutnya dilakukan optimasi topologi dengan memilih beberapa variasi area desain yang menghasilkan reduksi massa dalam variasi pertama sebesar $0,72 \mathrm{~kg}$ dan pada variasi kedua $1,49 \mathrm{~kg}$. Reduksi massa tersebut menyebabkan perubahan tegangan yang terjadi pada bucket tooth menjadi 451,8 MPa pada variasi pertama, dan 458,6 MPa pada variasi kedua, namun tegangan tersebut masih dalam kondisi aman.

Kata kunci: Bucket tooth; metode elemen hingga; optimasi topologi.

\section{Pendahuluan}

Bucket tooth merupakan salah satu bagian penting pada excavator dikarenakan memiliki peran utama saat proses penetrasi atau penggalian [1]. Bagian ini sering mengalami kontak langsung dengan medan penggalian yang berbedabeda. Oleh karena itu sifat mekanis bucket tooth harus kuat, keras dan tahan aus. Namun, disamping sifatnya tersebut sebuah bucket tooth perlu diganti setelah melalui periode kerja tertentu yang menyebabkan meningkatnya biaya operasional [2]. Maka dari itu penulis melakukan optimasi desain pada bucket tooth yang telah ada di pasaran agar dapat menghasilkan desain yang lebih ringan, sehingga dapat mengurangi kadar material bucket tooth yang terbuang akibat waktu pergantian.

Dalam penelitian ini perancangan desain menggunakan pendekatan dari desain asli yang didapat dari pasaran. Untuk properties material yang akan diinput dalam simulasi, penulis merujuk pada penelitian yang dilakukan oleh Arief yang menjelaskan bahwa material bucket tooth yang dia uji adalah AISI 4140 [3]. Dalam simulasi ini digunakan metode linear statik untuk proses optimasi. Optimasi yang dilakukan adalah optimasi topologi. Tujuan utama dari proses optimasi topologi ini adalah untuk mengurangi volume dari design variable yang telah ditentukan dengan cara memaksimalkan 
nilai kekakuan dari struktur yang diizinkan [4-5]. Fungsi objektif dari optimasi topologi merupakan nilai fungsi linear dari equilibrium displacement field, fungsi linear ini disebut compliance yang merupakan inverse dari nilai kekakuan sehingga ketika nilai compliance minimum didapatkan nilai kekakuan maksimum [6].

\section{Material dan Metode Penelitian}

\subsection{Identifikasi Material}

Pada penelitian ini, penentuan material bucket tooth yang digunakan merujuk pada penilitian Muhammad Arief yang membahas tentang karakterisasi material pada bucket tooth yang sudah ada di pasaran, yaitu AISI 4140 [3]. Data-data yang diperoleh dari penelitian tersebut diperlukan dalam proses optimasi desain bucket tooth kali ini. Data tersebut dapat dilihat pada Tabel 1 sebagai berikut.

Tabel 1. Data Karakteristik material AISI 4140 [3].

\begin{tabular}{clc}
\hline No. & Data karakteristik AISI 4140 & Nilai \\
\hline 1 & Modulus Elastisitas (E) & $205 \mathrm{GPa}$ \\
2 & Poisson Ratio & 0.29 \\
3 & Massa Jenis & $7.85 \mathrm{e}-08$ \\
4 & Yield Strength & 1515 \\
\hline
\end{tabular}

\subsection{Diagram Alir}

Pada penelitian ini terdapat langkah-langkah simulasi linear statik dan optimasi bucket tooth yang mengacu pada diagram alir Gambar 1.

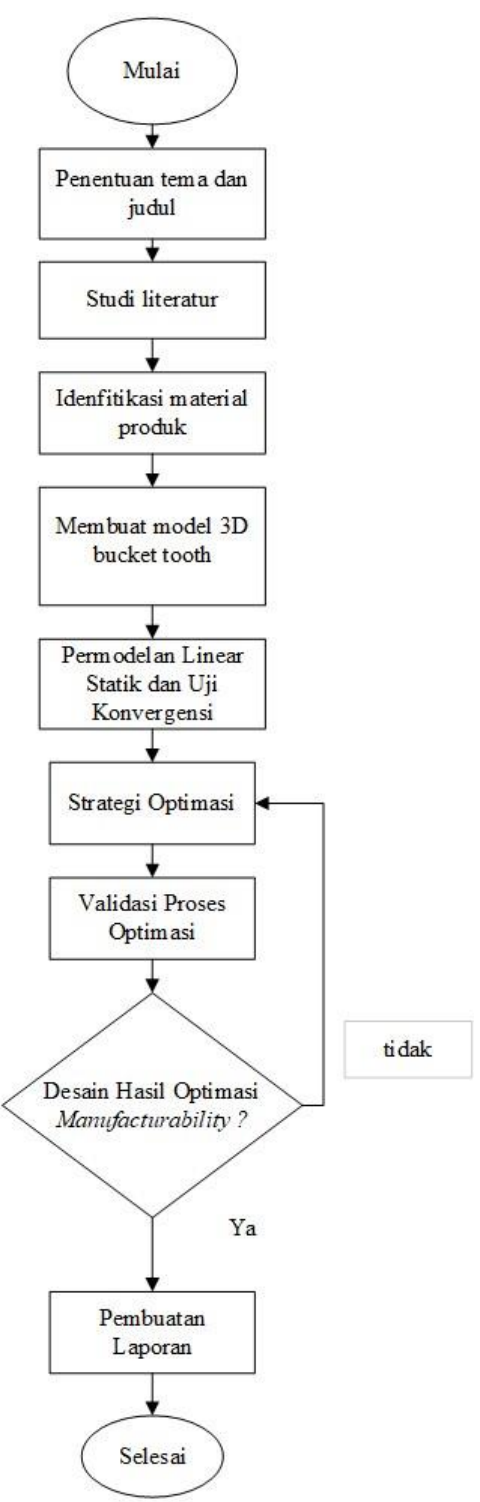

Gambar 1. Diagram Alir 


\subsection{Proses Permodelan 3D Bucket Tooth}

Bucket tooth yang dipakai dalam penelitian ini adalah bucket tooth jenis Verona PC200 seperti pada Gambar 2 (a). Pembuatan desain bucket tooth menggunakan software CAD dengan menggunakan pendekatan dari desain aslinya. Pada Gambar 2 (b) diperoleh hasil desain 3D bucket tooth. Software CAD yang digunakan untuk memodelkan adalah Solidworks 2016.

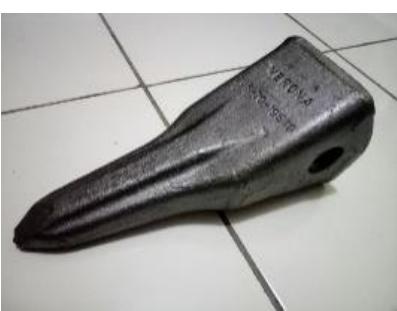

(a)

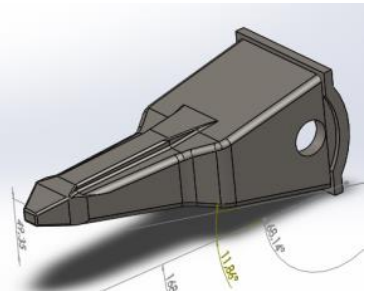

(b)

Gambar 2 Desain bucket tooth, (a) Verona PC200, (b) Hasil Desain CAD

\subsection{Pemodelan Linear Statik dan Uji Konvergensi}

Permodelan linear statik dipengaruhi oleh suatu gaya yang bekerja pada bucket tooth. Pada penelitian ini gaya diperoleh dari bucket curling force $(\mathrm{Fb})$ [7] pada excavator Komatsu PC200 sebesar 157000 N. Diketahui bahwa jumlah bucket tooth pada bucket sebanyak 5 unit, sehingga gaya $\mathrm{Fb}$ tersebut dibagi ke 5 unit yang menghasilkan gaya $31400 \mathrm{~N}$ pada setiap bucket tooth. Untuk kondisi maksimum, gaya terjadi pada sudut 32 derajat terhadap bucket tooth sehingga menimbulkan arah gaya seperti pada Gambar 3.

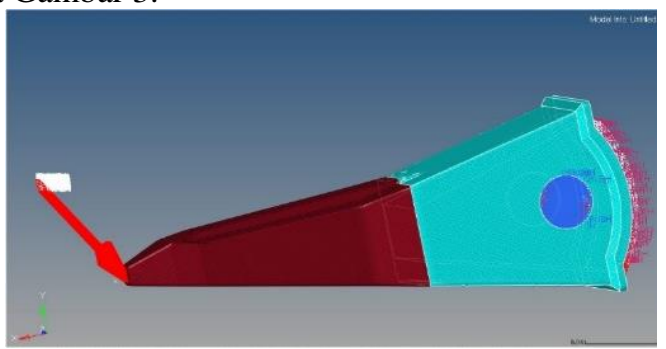

Gambar 3. Bucket curling force pada permodelan linear statik

\subsection{Proses Optimasi}

Metode optimasi yang digunakan merupakan optimasi topologi menggunakan perangkat lunak altair optistruct [5]. Pada desain bucket tooth dilakukan optimasi topologi dikarenakan bentuknya merupakan struktur 3D continuum dan optimasi topologi menghasilkan pengurangan massa yang lumayan besar. Berikut ini adalah langkah-langkah menentukan strategi optimasi topologi:

1) Menentukan design variable

Penentuan design variable bertujuan untuk menentukan bagian dari desain yang dapat diubah secara optimal. Pada penelitian ini terdapat dua variasi pemberian design variable untuk dibandingkan hasilnya yang dapat dilihat pada Gambar 4. Warna biru menunjukan design variable sedangkan warna merah menunjukan bagian non-design variables atau daerah yang tidak bisa dirubah.

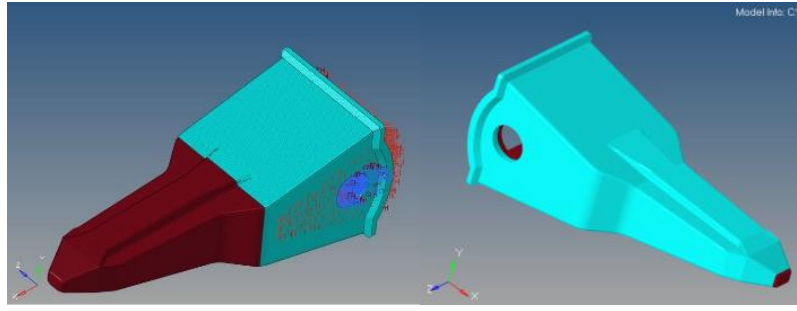

(a)

(b)

Gambar 4. Design variable 1 (a); Design variable 2 (b)

2) Menentukan Constraint

Desain constraint merupakan batasan yang terikat dengan respon agar hasil optimasi bisa diterima. Pada optimasi ini desain constraint berupa volume fraction sebesar $70 \%$.

3) Menentukan Respon Struktur

Respon merupakan perhitungan performa sistem yang kita tentukan sesuai dengan constraint dan objective dari apa yang akan kita tentukan. Pada proses optimasi ini respon yang digunakan berupa weight compliance dan volume fraction. 
4) Menentukan Objective

Objective merupakan tujuan setiap fungsi respon yang akan dioptimalkan, responnya merupakan variabel dari desainnya. Pada optimasi ini objektifnya berupa minimize weight compliance.

5) Menentukan Manufacturing Constraint

Kekhawatiran dalam optimasi topologi adalah konsep desain dikembangkan sering tidak dapat diproduksi. Optistruct menawarkan sejumlah metode berbeda untuk memperhitungkan kemampuan manufaktur ketika melakukan optimasi topologi [5]. Oleh karena itu manufacturing constraint harus ditentukan agar hasil optimasi dapat di manufaktur, dengan cara menentukan :

a. Minimum member size control

Minimum member size control digunakan untuk menentukan dimensi terkecil yang harus dipertahankan dalam desain topologi. Pada penelitian ini ditentukan nilai minimum member size control senilai 0,16 mm.

b. Draw Direction

Draw direction digunakan untuk mendapatkan desain yang cocok jika dilakukan proses casting. Dalam prosesnya rongga-rongga yang tidak terbuka dan searah dengan arah geser dari die tidak diperbolehkan.

c. Pattern Grouping

Pattern grouping adalah fitur untuk menentukan satu bagian dari domain yang harus dirancang dalam pola tertentu, misalkan untuk mendapatkan desain simetris bahkan jika beban yang diterapkan pada struktur tidak simetris. Pada penelitian ini menggunakan symmetry pattern grouping.

\section{Hasil Dan Pembahasan}

\subsection{Hasil Simulasi Linear Statik}

Untuk mengetahui apakah material yang digunakan tidak mengalami kegagalan dan dapat dioptimasi dilakukan analisa linear statik untuk mendapatkan nilai von-mises dari suatu desain dengan material yang didapatkan dari hasil identifikasi [8]. Hasil analisa linear statik dapat dilihat pada Gambar 5. Berdasarkan hasil simulasi linear statik nilai vonmises yang dihasilkan sebesar 403,39 $\mathrm{MPa}$.

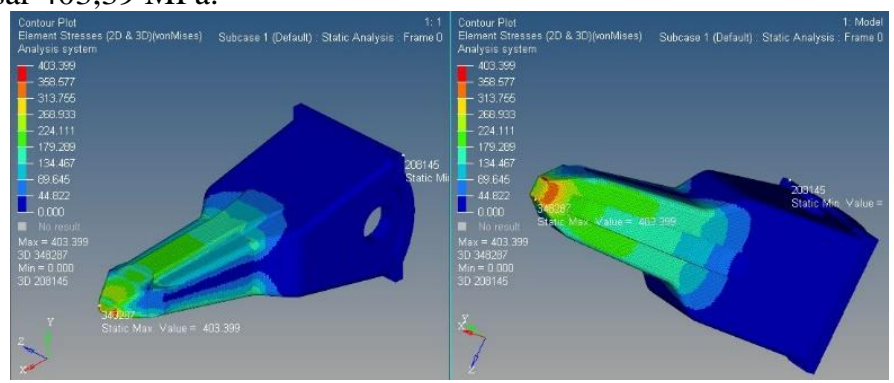

Gambar 5. Nilai von-mises bucket tooth Verona PC200

\subsection{Hasil Uji Kovergensi}

Untuk menentukan jumlah elemen yang sesuai untuk dilanjutkan dengan proses optimasi dilakukan uji konvergensi terlebih dahulu [9] yang dapat dilihat pada Tabel 2 sampai didapat hasil yang konvergen pada setiap kenaikan elemen dengan melakukan perbaikan mesh secara bertahap dan pada daerah tertentu.

Tabel 2. Nilai tegangan maksimum von mises tiap elemen

\begin{tabular}{ccc}
\hline No & Tegangan Maksimum (MPa) & Jumlah Elemen \\
\hline 1 & 385.798 & 137.181 \\
2 & 400.047 & 144.937 \\
3 & 407.501 & 151.890 \\
4 & 403.968 & 429.426 \\
5 & 403.309 & 447.866 \\
\hline
\end{tabular}

Berdasarkan variasi kenaikan elemen pada Tabel 2 diatas, semakin elemen bertambah maka tegangan yang terjadi tetap sama, sehingga dapat disimpulkan bahwa pada elemen-elemen tersebut menunjukan sudah konvergen. Pada penelitian ini menggunakan elemen paling banyak pada hasil uji konvergensi ke-5, yaitu 447.886. Berikut ini adalah gambar distribusi tegangan yang terjadi pada bucket tooth. 


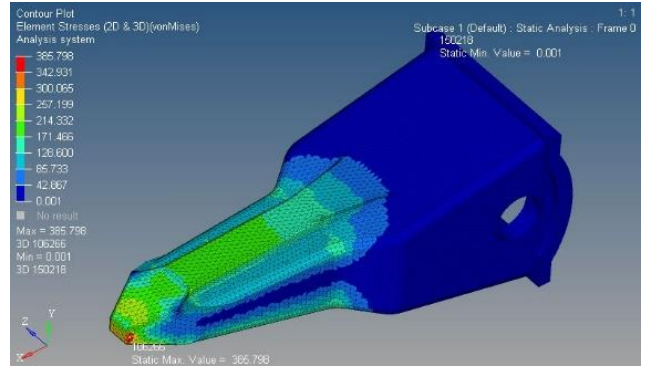

Gambar 6. Nilai von-mises uji konvergensi 1.

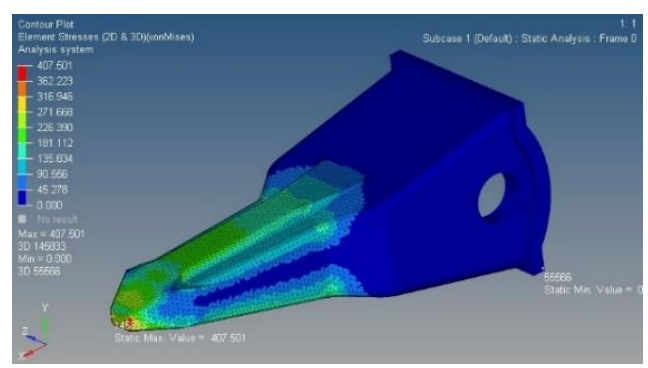

Gambar 8. Nilai von-mises uji konvergensi 3.

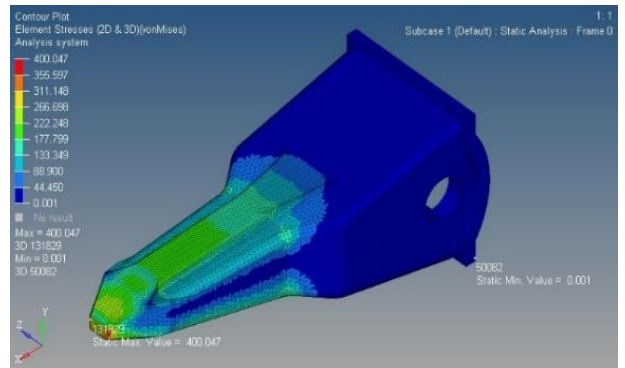

Gambar 7. Nilai von-mises uji konvergensi 2.

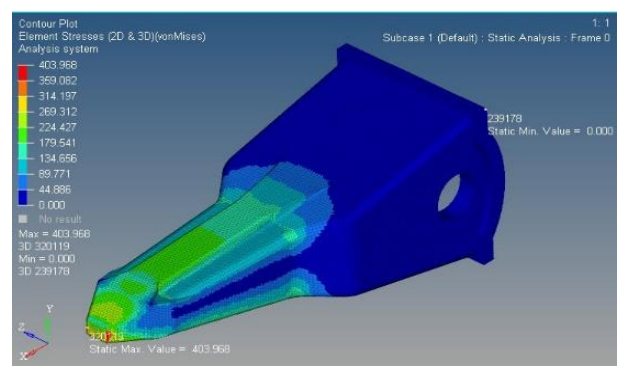

Gambar 9. Nilai von-mises uji konvergensi 4.

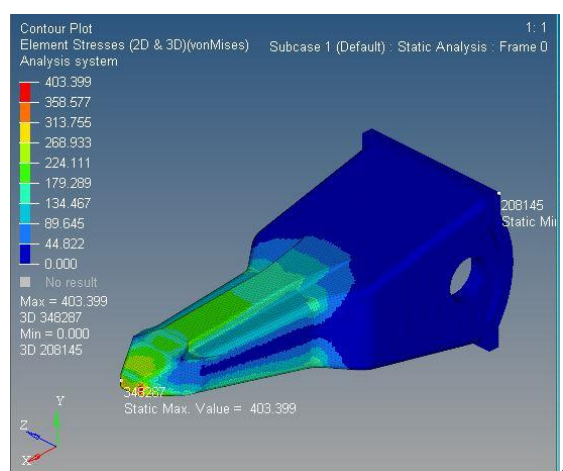

Gambar 10. Nilai von-mises uji konvergensi 5.

\subsection{Hasil Optimasi Topologi}

Hasil optimasi diilustrasikan pada Gambar 11 dan Gambar 12 dengan elemen $\rho>0,5$ dimana material dihilangkan dari bagian yang tidak terlalu dipengaruhi oleh gaya yang diberikan sehingga diperoleh bucket tooth yang lebih ringan dengan tegangan yang tidak berbeda jauh. Pada hasil optimasi desain variabel 2 mengalami sedikit kenaikan pada tegangan maksimum von-mises namun masih dibawah 5\% sehingga masih dapat diterima.

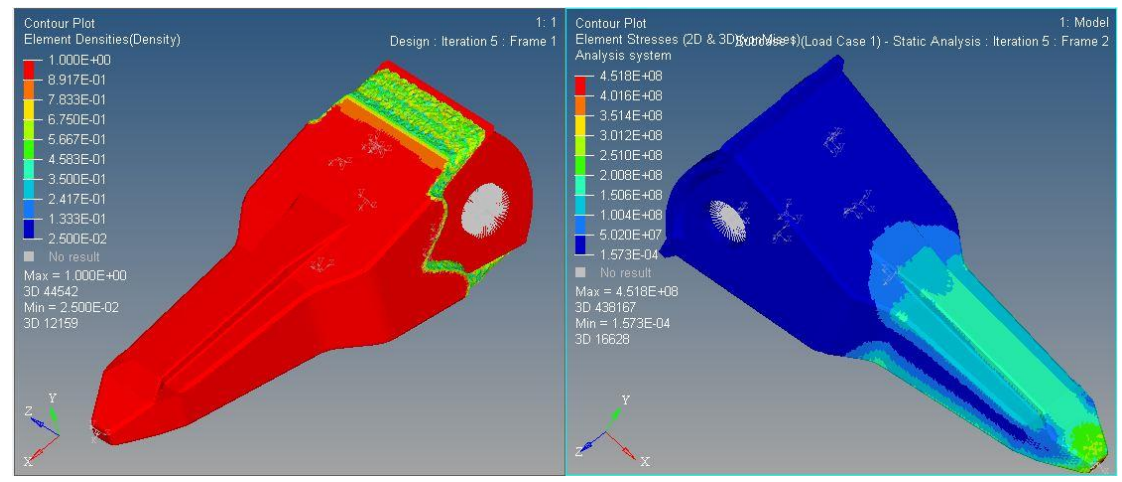

Gambar 11. Hasil optimasi topologi desain variabel 1. 


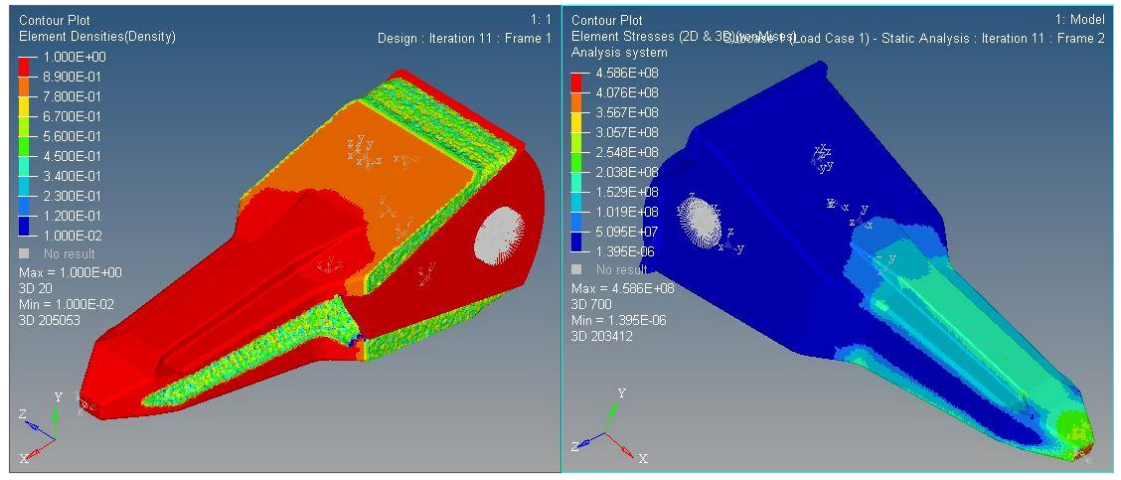

Gambar 12. Hasil optimasi topologi desain variabel 2.

Hasil optimasi diatas dapat diketahui secara komputasional melalui grafik weight compliance pada hasil optimasi desain variabel 1 dengan desain variabel 2 yang ditunjukkan Gambar 13 dan Gambar 14.

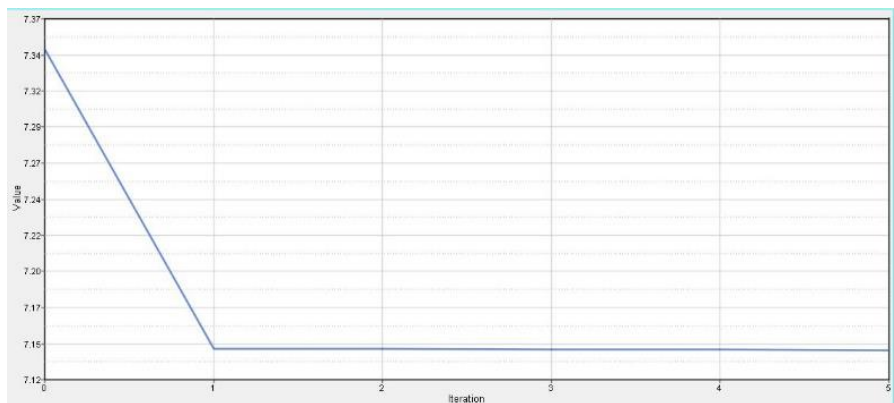

Gambar 13. Grafik nilai compliance desain variabel 1.

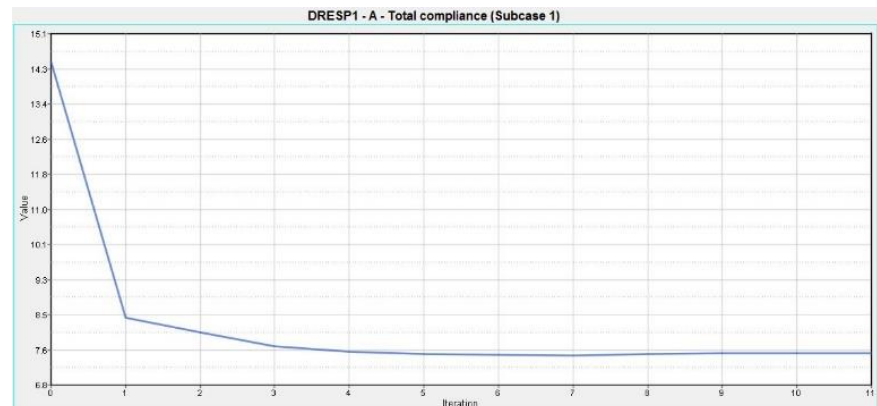

Gambar 14. Grafik nilai compliance desain variabel 2.

\subsection{Pembahasan Hasil Optimasi Topologi}

Optimasi topologi merupakan salah satu bentuk optimasi yang sering diterapkan pada suatu struktur [10]. Pengaplikasian optimasi topologi pada penelitian ini bertujuan untuk merubah desain bucket tooth jenis Verona PC200 menjadi desain yang lebih ringan. Pendekatan yang dipakai menggunakan metode distribusi elemen density atau SIMP method yang merubah struktur bucket tooth yang kontinum menjadi struktur diskrit berupa elemen-elemen [11]. Dengan metode tersebut dapat menghasilkan desain bucket tooth yang lebih ringan dan optimal. Hal tersebut ditunjukan dengan perbandingan hasil optimasi desain antara desain awal dan desain setelah optimasi pada Tabel 3 berikut.

Tabel 3. Perbandingan desain awal dan sesudah optimasi.

\begin{tabular}{lcc}
\hline Pembanding & Desain variabel 1 & Desain variabel 2 \\
\hline Massa awal & $6,25 \mathrm{~kg}$ & $6,25 \mathrm{~kg}$ \\
$\begin{array}{l}\text { Massa setelah } \\
\text { optimasi }\end{array}$ & $5,53 \mathrm{~kg}$ & $4,97 \mathrm{~kg}$ \\
$\begin{array}{l}\text { Tegangan maksimum } \\
\text { awal }\end{array}$ & $403,31 \mathrm{MPa}$ & $403,31 \mathrm{MPa}$ \\
$\begin{array}{l}\text { Tegangan maksimum } \\
\text { setelah optimasi }\end{array}$ & $451,8 \mathrm{MPa}$ & $458,6 \mathrm{MPa}$ \\
Safety factor & 3,35 & 3,30 \\
\hline & & $242 \mid \mathrm{ROTASI}$
\end{tabular}




\section{Kesimpulan}

Berdasarkan hasil penelitian yang telah dilakukan maka dapat dismpulkan bahwa setelah dilakukan simulasi linear statik menggunakan metode elemen hingga didapatkan nilai tegangan maksimum von-mises sebesar 403,81 MPa. Dari hasil optimasi topologi didapatkan penurunan massa pada desain variabel pertama sebesar $0.72 \mathrm{~kg}$ dan pada desain variabel 2 sebesar 1,49 kg. Selain itu tegangan maksimum von-mises pada variasi 1 mengalami peningkatan menjadi sebesar 451,8 Mpa, sedangkan pada variasi 2 sebesar 458,6 Mpa. Akibat dari peningkatan tegangan tersebut membuat nilai safety factor dari desain variabel pertama bernilai 3,35 dan desain variabel kedua bernilai 3,30 dimana bisa dikatakan nilai dari tegangan yang terjadi pada kedua desain walaupun cenderung naik tetapi masih dinyatakan aman. Jika dibandingkan antara kedua hasil optimasi dari kedua desain bahwa yang paling optimal dari aspek wear-life adalah hasil dari variasi design variable pertama, sedangkan untuk aspek optimasi compliance adalah hasil dari variasi design variable kedua.

\section{Daftar Pustaka}

[1] B. P. Shaikh," Analysis of Bucket Teeth of Backhoe Excavator Loader and its Weight Optimization" International Journal of Engineering Research \& Technology, Vol. 4 Issue 05, 2015

[2] Fernandez J.E., Vijande R., Tucho R., Rodriguez J., Martin A., "Materials selection to excavator tooth in mining industry" Elsevier, Wear, pp. 11-18, 2001.

[3] Muhammad Arief R.R, "Analysis of AISI material power of AISI 4140 bucket teeth excavator using influence of abrasive wear", AIP Conference Proceeding, 2018.

[4] Altair HyperWorks $\quad$ Help. $\quad$ [Referred 10.4.2013]. Available: http://www.altairhyperworks.com/hwhelp/Altair/hw12.0/index.aspx

[5] Altair Optimization Guide Book, Practical Aspect of Structure Optimization, 2015.

[6] Bendsøe, M.P. Sigmund, O, Topology Optimization. Theory, Methods and Applications. Berlin Heidelberg, Germany: Springer-Verlag, 2003, ISBN 3-540-42992-1.

[7] SAE J1179: Hydraulic Excavator and Backhoe Digging Force. Warrendale: SAE International, 1990.

[8] Dagwar, K. S. Telrandhe, R. G. "Failure Analysis of Excavator Bucket Tooth." International Journal of Scientific Research and Engineering Studies, pp. 2349-8862, vol.5, 2015.

[9] Oñate, E. "Structural Analysis with the Finite Element Method." Linear Statics Lecture Notes on Numerical Methods in Engineering and Sciences. Barcelona: Artes Gráficas Torres S.A., 2003.

[10] Selley, et all, Engineering Optimization. Budapest, 2012.

[11] Christensen, Peter W. Klarbring, A. "An Introduction to Structural Optimization”. Berlin Heidelberg, Germany: Springer-Verlag. ISBN-13: 978- 1402086656, . 2008. 